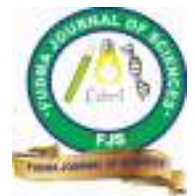

FUDMA Journal of Sciences (FJS)

ISSN online: $2616-1370$

ISSN print: 2645 - 2944

Vol. 4 No. 3, September, 2020, pp $201-206$

DOI: https://doi.org/10.33003/fjs-2020-0403-386

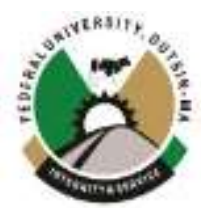

\title{
GENETIC RELATEDNESS OF ESBL AND NON-ESBL SALMONELLA TYPHIMURUM ISOLATED FROM POULTRY BIRDS AND POULTRY HANDLERS IN NASARAWA STATE, NIGERIA.
}

\author{
${ }^{* 1}$ T. Ibrahim, ${ }^{2}$ Y. B. Ngwai, ${ }^{2}$ D. Ishaleku, ${ }^{2}$ P. A. Tsaku, ${ }^{2}$ I. H. Nkene, ${ }^{3}$ R. H. Abimiku \\ ${ }^{1}$ Department of Science Laboratory Technology, Nasarawa State University, Keffi, Nasarawa State, Nigeria. \\ ${ }^{2}$ Department of Microbiology, Nasarawa State University, Keffi, Nasarawa State, Nigeria. \\ ${ }^{3}$ Human Virology Research Centre, Jos, Plateau State, Nigeria. \\ *Correspondence Author E-mail: Taibat1006@gmail.com
}

\begin{abstract}
Multidrug resistant salmonellosis infection is an important global public health problem particularly in subSaharan Africa, where it commonly manifests as gastroenteritis and/or bloodstream infections in both children and adults. Salmonella Typhimurium has a broad-host-range and poultry birds are an important reservoir. The unrestricted use of Beta-lactams has generated resistance through a gene encoded Extended Spectrum Beta-lactamase (ESBL) enzyme production, which impedes the successful therapy of infections. This study aims at investigating the genetic relatedness of ESBL and non-ESBL S. Typhimurium strains isolated from humans and Poultry birds. A total of $19 \mathrm{~S}$. Typhimurium isolated from Poultry (droppings, flesh, feeds) and handlers (feces, hand swabs) in a previous study were used. These had earlier been identified using pre-enrichment and selective enrichment culture media. Further identification was carried out using conventional biochemical screening tests and slide serology tests using polyvalent antisera. Antibiotic susceptibility testing including the Double Disk Synergy test (DDST) for screening of ESBL production was carried out as described by the Clinical and Laboratory Standards Institute (CLSI) guidelines. This study also employed the PCR-RFLP method which involves the simple restriction digestion of purified 16S rRNA of Salmonella and variation in the banding patterns revealed their genetic relatedness. All the strains were found to share identical molecular base profiles hence are genetically related variants. The selective pressure due to antibiotic mismanagement in Poultry farming is the likely trigger of ESBL production observed to occur only among the $S$. Typhimurium strains from poultry origin. This calls for a holistic approach in antibiotic stewardship.
\end{abstract}

Keywords: Genetic relatedness, PCR-RFLP, 16S rRNA gene, ESBL, salmonella typhimurium, Nasarawa, poultry.

\section{INTRODUCTION}

Salmonella enterica is a zoonotic pathogen which can readily pass from animal to man through the consumption of contaminated foods (Cosby et al., 2015; Card et al., 2016). Majority of over 2650 recognized serotypes of Salmonella infect both humans and animals worldwide with signs ranging from fever, abdominal cramps, vomiting, diarrhea and death (Guibourdenche et al., 2010; Scallan et al., 2011; IssenhuthJeanjean et al., 2014). Poultry is an important source of antimicrobial resistant bacteria including the ESBL-producing Salmonella (Oyinloye et al., 2011). Production of ESBLs is a significant resistance mechanism that impedes the antimicrobial therapy of infections caused by some Enterobacteriaceae and is a serious threat to the currently available antimicrobial options (Shaikh et al., 2015). Salmonella strains, affecting both humans and animals exhibiting resistance to many of the currently available antibiotics used in therapy have emerged and are increasing in frequency with more hospitalization. This has serious implications for farmers, consumers of food animals and the public health (Lu et al., 2014; Mukherjee et al., 2019). Therefore, identifying and typing these strains are key steps in the successful therapy of salmonellosis infections as well as for epidemiological purpose (Turki et al., 2014).

Multiple typing methods are available and used for discriminating microorganisms at strain level based on either phenotypic or genotypic traits. The phenotypic method includes biotyping, serotyping, phage typing, antibiotic susceptibility testing, mass spectrometry (MS) and sodium dodecyl sulphate-polyacrylamide gel electrophoresis (SDSPAGE) of cellular-extracellular components. Whereas the genotypic methods target the nucleic acid, and involves use of the Polymerase Chain Reaction-Restriction Fragment Length Polymorphism (PCR-RFLP), Pulsed Field Gel Electrophoresis (PFGE), Random Amplified Polymorphic DNA (RAPD), Amplified Fragment Length Polymorphism (AFLP), ribotyping, multilocus sequence typing and multiplex PCR (Neslihan et al., 2018). The current gold standard for molecular typing is Pulse-Field Gel Electrophoresis (PFGE), which can provide discrimination between similar serotypes and is the basis for PulseNet surveillance (Soler-García et al., 2014). Unfortunately, PFGE is a laborious, time-consuming, and expensive method. A sub-typing method should be rapid, robust, portable and sensitive. It should be able to reliably differentiate epidemiologically unrelated strains from each other and group all isolates associated with the same source without disrupting their classification into subspecies and serovars (Soler-García et al., 2014). Such a sub-typing system would also need to be within budgets of laboratories, researchers and students especially in the developing Countries. It is also required to be less time consuming for prompt identification and commencement of therapy in the event of an outbreak. 
Polymerase Chain Reaction-Restriction fragment length polymorphism (PCR-RFLP) is a variation of RFLP which is one of the easiest ways to study diversity of microbes (Chatterjee, 2019). The technique uses the simple restriction enzyme digestion of purified DNA from bacteria, and variation in the banding pattern in the digestion reveals the genetic diversity. The $16 \mathrm{~S}$ rRNA and $23 \mathrm{~S}$ rRNA are the most widely used molecular chronometers. For adequate discrimination, the amplified region or gene needs to have a variable region flanked by conserved regions to allow PCR amplification and generation of different restriction patterns after cutting with restriction enzymes (Soler-García et al., 2014). PCR-RFLP has been successfully used for the study of diversity of $V$. cholerae strains (Chowdhury et al., 2010). In a recent study, it was stated that RFLP can be used to study taxonomy of $Y$. pestis, $S$. aureus coagulase gene diversity from food products, as well as diversity in the plasmid from $E$. coli which was isolated from water source (Qi et al. 2016 ; Dallal et al.2016) as cited in Chatterjee \& Rajal (2019). Neslihan et al. (2018) also used PCR-RFLP to determine the genetic variability of 38 foodborne Salmonella isolates that were previously identified by biochemical tests.

Backyard poultry farms are a common sight in our study area and are mostly practiced under low levels of hygiene. There is a risk of infection and cross contamination with antibiotic resistant $S$. Typhimurium strains harbored in the guts of these birds with food, beverages, water, fruits and vegetables consumed by Man. Successful antibiotic therapy of such infections can be achieved when the variant of the strains implicated are properly identified and typed by adopting one of the phenotypic and/or genotypic typing methods. To the best of our knowledge, no study has been done in north central Nigeria using the PCR-RFLP method to determine the genetic relatedness between the ESBL and non-ESBL $S$. Typhimurium strains from poultry and their handlers as an attempt to adopt a cheap and reliable means of prompt laboratory diagnosis of multidrug resistant or ESBL salmonellosis infections.

The study aimed at using PCR-RFLP method to study the genetic relatedness of Salmonella Typhimurium strains isolated from poultry birds and their handlers which were previously exposed to critically important antibiotic groups used for therapy in both human and veterinary medicine.

\section{MATERIALS AND METHODS}

\section{Bacterial strains, media and growth conditions}

A total of 19 multidrug resistant (MDR) S. Typhimurium isolates earlier characterized from a previous study (Ibrahim et al., 2019) were selected for this study. However, out of the selected isolates, 16 were ESBL- producers from poultry birds, while the remaining 3 were non-ESBL producers from poultry farm workers. The isolates were stored in sterile nutrient agar slants at $4^{\circ} \mathrm{C}$. The Salmonella strains were grown overnight $(18 \mathrm{~h})$ under aerobic conditions at $37^{\circ} \mathrm{C}$ in XLD (Oxoid Ltd, Hampshire, UK).

\section{Primers}

The 16S rRNA primer used in this study as listed in Table 1.

Table 1: Primer for 16S rRNA gene of Salmonella

\begin{tabular}{llll}
\hline Primer & Sequence (5' - 3') & Amplicon length (bp) & Reference \\
\hline 16S rRNA & F: AGAGTTTGATCMTGGCTCAG & 27 & Jiang et al., 2006 \\
& R:CGGTTACCTTGTTACGACTT & 1492 & \\
\hline
\end{tabular}

Key: $b p=$ base pairs

DNA extraction (Boiling method): Bacterial culture was inoculated into sterile Luria-Bertani (LB) broth and incubated at $37^{\circ} \mathrm{C}$ for $8 \mathrm{~h}$. Five millilitres of the $\mathrm{LB}$ broth culture containing the bacterial isolates was spun at $14000 \mathrm{rpm}$ for 3 min. The cells were resuspended in $500 \mu 1$ of normal saline and heated at $95^{\circ} \mathrm{C}$ for $20 \mathrm{~min}$ in the heating chamber. The heated bacterial suspension was cooled on ice and thereafter spun for $3 \mathrm{~min}$ at $14000 \mathrm{rpm}$. The supernatant containing the DNA was transferred into a 1.5-ml micro centrifuge tubes and stored at $20^{\circ} \mathrm{C}$ for subsequent experimentations (Ghorbani-Dalini et al., 2015).

DNA Quantification: The extracted genomic DNA was quantified using the NanoDrop 1000 spectrophotometer by placing a drop (approximately $2 \mu \mathrm{l}$ ) on the sample space and analysed using the NanoDrop 1000 software. For DNA concentration, absorbance readings were performed at $260 \mathrm{~nm}$ (A260) and the readings were observed to be within the instrument's linear range $(0.1-1.0)$. DNA purity was estimated by calculating the $\mathrm{A}_{260} / \mathrm{A}_{280}$ ratio and this was done by the spectrophotometer's computer software (where $\mathrm{A}_{260} / \mathrm{A}_{280}$ ratio ranges from 1.7 - 1.9).
Restriction Fragment Length Polymorphism (RFLP) analyses

16S rRNA gene Amplification: The 16s rRNA region of the rRNA genes of the bacterial isolates were amplified using the universal 16s rRNA gene primers listed previously (Table 1) in a thermal cycler at a final volume of $25 \mu \mathrm{l}$ for 35 cycles. The PCR mix included: X2 Dream Taq Master Mix supplied by Inqaba, South Africa (Taq polymerase, DNTPs, $\mathrm{MgCl}_{2}$ ), the primers at a concentration of $0.2 \mathrm{M}$ and the extracted DNA as template. The PCR conditions were as follows: Initial denaturation, $95^{\circ} \mathrm{C}$ for $5 \mathrm{~min}$; denaturation, $95^{\circ} \mathrm{C}$ for $30 \mathrm{sec}$; annealing, $52^{\circ} \mathrm{C}$ for $30 \mathrm{sec}$; extension, $72^{\circ} \mathrm{C}$ for $30 \mathrm{sec}$ for 35 cycles and final extension, $72^{\circ} \mathrm{C}$ for $5 \mathrm{~min}$. The product was resolved on a $1.5 \%$ agarose gel at $120 \mathrm{~V}$ for $20 \mathrm{~min}$ and visualized on a UV transilluminator.

Restriction enzyme digestion of the 16S rRNA gene: The method of Lacher et al. (2006) was adopted for RFLP to identify genetic diversity of the $S$. Typhimurium isolates. To achieve species-specific discriminatory patterns, a $5 \mu 1$ aliquot of 16S rRNA gene PCR amplicons were enzymatically digested with $10 \mathrm{U} / \mu 1$ of Eco 471 and $B s G r$ separately (AvaII ThermoFisher Scientific) in a final volume of $25 \mu 1$ at $37^{\circ} \mathrm{C}$ for $6 \mathrm{~h}$. The restriction fragments were separated on $2 \%$ agarose gel electrophoresis in TBE buffer for about $30 \mathrm{~min}$ at $120 \mathrm{~V}$ and visualized by staining with $0.5 \mu \mathrm{g} / \mathrm{ml}$ of ethidium bromide. 
Determination of genetic relationship between ESBL and Non-ESBL $S$. Typhimurium strains from Poultry and Poultry farm workers

The genetic relationship between $S$. Typhimurium isolates from Poultry and Poultry farm workers was further determined by an analysis of the PCR-RFLP profiles presented as a Dendrogram.

\section{RESULTS}

Analysis of the genetic relatedness between the ESBL and Non-ESBL S.Typhimurium strains using PCR-RFLP endonulease enzymes generated molecular profiles which are summarized as shown in Tables 1-2 and Plates 1-2 respectively.

Table 1: PCR-RFLP Profiles of Eco 471 endonuclease digestion of 16S rRNA of the S.Typhimurium strains isolated from Poultry (droppings, feeds, flesh) and Poultry farm handlers ( feces and hand swab) in Nasarawa State

\begin{tabular}{lcccc}
\hline Isolate ID & No. of Isolates & Eco 471 Profiles & No. of bands & RFLP \\
Pattern/Variant
\end{tabular}

\begin{tabular}{|c|c|c|c|c|}
\hline P1-P5, P7-P9, P15, P16 & 10 & $380-700$ & 2 & A \\
\hline $\mathrm{H} 1, \mathrm{H} 2, \mathrm{H} 3$ & 3 & $380-700$ & 2 & A \\
\hline P14 & 1 & $380-490-750$ & 3 & $\mathrm{~B}$ \\
\hline P6,P10 & 2 & $350-750$ & 2 & A \\
\hline $\mathrm{P} 11, \mathrm{P} 12, \mathrm{P} 13$ & 3 & $380-500$ & 2 & A \\
\hline Total & 19 & & & \\
\hline
\end{tabular}

Key: ID = Identity, $\mathrm{P}=$ Poultry, $\mathrm{H}=$ Handlers

Table 2: PCR-RFLP Profiles of BsGr endonuclease digestions of 16S rRNA of the S.Typhimurium strains isolated from Poultry (droppings, feeds, flesh) and Poultry farm handlers ( feces and hand swab) in Nasarawa State

\begin{tabular}{lcccc}
\hline Isolate ID & No. of Isolates & $\boldsymbol{B s} \boldsymbol{G} \boldsymbol{r}$ Profiles & No. of bands & $\begin{array}{l}\text { RFLP } \\
\text { Pattern/Variant }\end{array}$ \\
\hline P1-P10,P15,P16 & 12 & $200-300-500$ & 3 & B \\
H1,H2,H3 & 3 & $200-300-500$ & 3 & B \\
P14 & 1 & $300-500$ & 2 & A \\
P11,P12,P13 & 3 & $200-400-500$ & 3 & \\
Total & 19 & & & \\
\hline
\end{tabular}

Key: ID = Identity, $\mathrm{P}=$ Poultry, $\mathrm{H}=$ Handlers

Gel Pictures for the PCR-RFLP

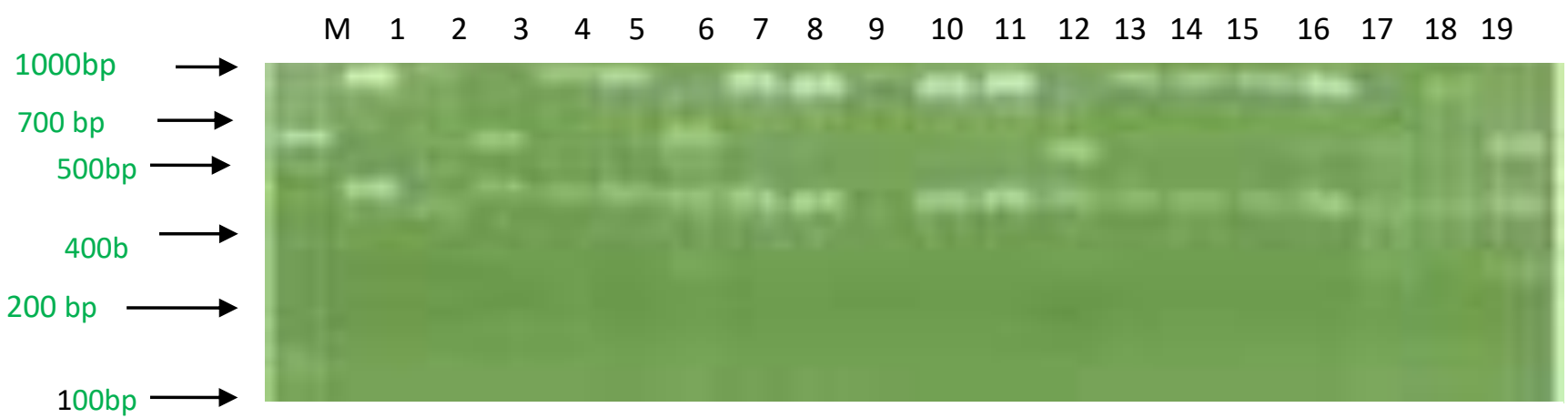

Plate 1: PCR-RFLP profiles of 16S rRNA gene of $S$.Typhimurium showing different bands pattern after digestion with Eco471. Lane 1, 4, 5, 7, 8, 10-11, 13-16, 18-19 (380-700 bp) represents isolates H1-H3, P1-P5, P7- P9, P15-16 Lane 2 and 9 (350-750bp) represent isolates P6 \& P10, Lane 3, 12, 17 (380-500bp) represent isolates 11,12 \&13, Lane 6 (380-490 -750)represents isolate $\mathrm{P} 14$, while M represents a 100bp ladder.

$$
\text { Key: } \mathrm{P}=\text { Poultry, } \mathrm{H}=\text { Handlers }
$$




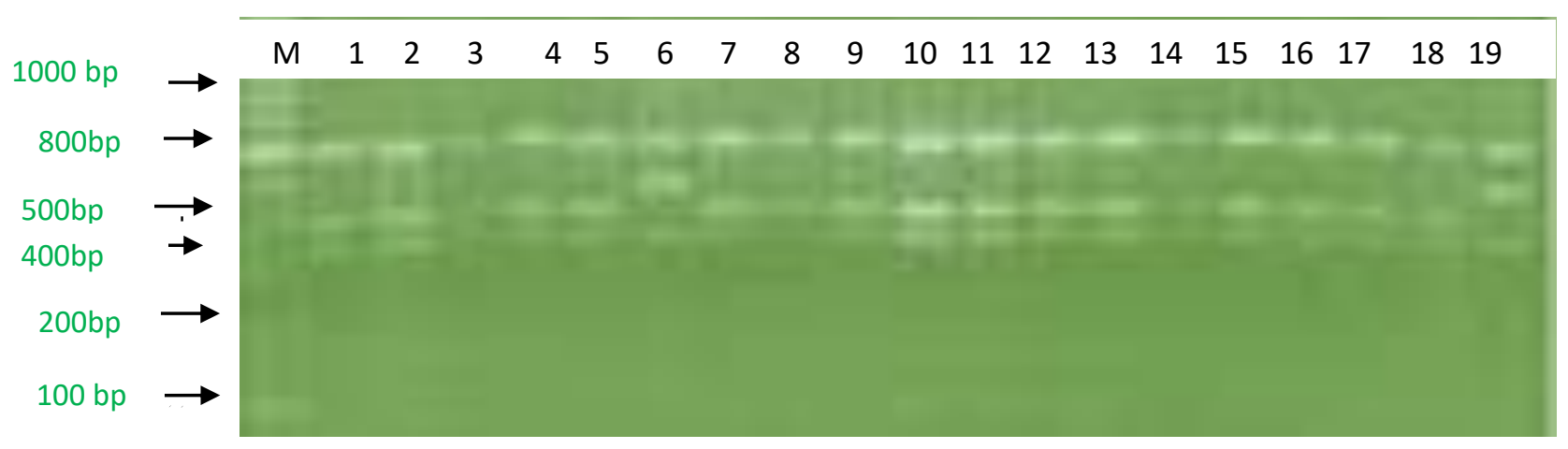

Plate 2: PCR-RFLP profiles of 16S rRNA gene of $S$.Typhimurium after digestion with $B s \mathrm{Gr}$ restriction endonuclease. Lane 1- 5, 7-17 and 18 (200-300-500 bp) represents isolates H1-3, P1P10, P12, P15, P16, Lane 8 (300-500 bp) represents isolate P14, Lane 6 and 19 (200-400- 500 bp) represents isolates $\mathrm{P} 11 \& \mathrm{P} 13$ while $\mathrm{M}$ represents a $100 \mathrm{bp}$ molecular ladder.

\begin{abstract}
DISCUSSION
Salmonella enterica serotype Typhimurium is documented to $\mathrm{s}$ ability to colonize and cause infections in a vast majority of animal species; humans, livestock, domestic fowl, rodents and birds (Rabsch et al., 2002; Feasey et al., 2012; WHO, 2018). Serotype $S$. Typhimurium variants with a narrow host range have also been documented (Rabsch et al., 2002). The PCRRFLP method employed for this study was able to discriminate the variants of ESBL and non-ESBL $S$.Typhimurium strains isolated from both poultry birds and their handlers. All the nonESBLs from poultry handlers and the ESBLs from poultry with the exception of two strains had similar number of molecular bands and also shared identical lengths of cleavage fragments. In addition, they occupied the same position in the cluster following analysis of the dendrogram. All these signify that they are genetically related variants with a common source of contamination. This is similar to the findings of Chenggang et al. (2017) in China where majority of Salmonella isolates from different sources possessed identical molecular finger prints, implying relatedness and a zoonotic transmission.
\end{abstract}

Similarly, results of the $B s G r$ endonuclease digestions revealed that all the ESBL and non-ESBL $S$.Typhimurium strains shared specific RFLP pattern of finger prints; $200 \mathrm{bp}$, $300 \mathrm{bp}$ and $500 \mathrm{bp}$ indicating a characteristic sequence of DNA. The results of their pattern similarities were further presented as a dendrogram which also grouped the fingerprints into same cluster hence, implies that the isolates are genetically related variants having a common source of contamination with a zoonotic characteristic. Our study finding indicated that the $B s G r$ endonuclease gave a better discrimination and produced a better digestion result with multiple interpretable PCR-RFLP patterns because this enzyme had more restriction sites for the $16 \mathrm{~S}$ r RNA gene compared to the Eco471 enzyme.

Interestingly, the ESBL $S$. Typhimurium variants were restricted to Poultry birds. It is likely that the selective pressure due to persistent exposure to antibiotics arising from its misuse and overuse triggered the evolvement of these variants. Antibiotics, particularly the beta-lactam groups are known to be incorporated in feed additives to serve as growth enhancers be a prototypical broad-host-range serotype as a result of it

and or prophylaxis against infections (Landers et al., 2012) in food animals. Colonization and infection of humans and othern animals with these particular variants can hamper the successful therapy of severe non-typhoidal salmonellosis infections using extended spectrum cephalosporins licensed for use in both human and veterinary medicine. In addition, their antibiotic resistance determinants can easily be transferred to other bacteria which can also stall the therapy of infections they cause. The occurrence of these variants of ESBL and nonESBL S. Typhimurium in our study area further highlights the role of proper organism identification, antibiotic susceptibility testing and typing of bacterial strains as key steps in successful therapy of salmonellosis infections as well as for epidemiological purpose.

The findings in the present study using PCR-RFLP with double endonuclease digestions agrees with the studies of Khaki et al. (2013), Dilmaghani et al. (2010) and Zaki et al. (2009). The studies of Sumithra et al. (2014), Khaki et al. (2013) and Matsuie et al. (2001) however, suggest that PCR-RFLP using more than one endonuclease and genes gives good typeability and increases the differentiating power. Although the studies of Neslihan et al. (2018) concluded that PCR-RFLP is a good typing method but lacked sufficient power of discrimination which is at variance with the present study findings. Nevertheless, researchers have employed PCR-RFLP for serotyping and analysis of diversity in microorganisms using different genes and double combinations of endonucleases to which they obtained varying results (Moradi et al., 2015).

The report of Akbarmehr et al. (2010) is contrary to our study findings probably due to differences in the endonuclease enzymes employed for both studies.

Further studies employing different sets of enzymes and genes in order to create more choices for a successful PCR-RFLP to study diversity among Salmonella serotypes is recommended. 


\section{CONCLUSION}

All the $S$. Typhimurium strains were found to share identical molecular base profiles hence are genetically related variants. However, the selective pressure due to beta-lactam antibiotic misuse and overuse in Poultry farming triggered ESBL production which was observed to occur among the $S$. Typhimurium strains isolated from poultry source (droppings, flesh and feeds). This calls for a holistic approach in antibiotic stewardship.

\section{REFERENCES}

Akbarmehr, J., Salehi, T.Z., \& Nikbakht Brujeni, G.N. (2010). Identification of Salmonella isolated from poultry by MPCR technique and evaluation of their hsp groEL gene diversity based on the PCR-RFLP analysis. African J Microbiol Res.4, 1594-98

Card, R., Vaughan K., Bagnall, M., Spiropoulos, J., Cooley, W., Strickland, T., Davies, R., \& Anjum, M.F. (2016). Virulence, Characterization of Salmonella enterica isolates of differing antimicrobial resistance recovered from UK Livestock and imported meat samples. Front Microbiol. (7), 640.doi:10.3389/fmicb.2016.00640

Chatterjee, S. \& Raval, I.H. (2019). Pathogenic Microbial Genetic Diversity with Reference to Health, in Microbial Diversity in the Genomic Era. Section I. In Surajit Das \& Hirak Dash (Eds.) Microbial Diversity in the Genomic Era. (pp 3-14). [e-book].Retrieved https://www.sciencedirect.com/topics/immunology-andmicrobiology/restriction-fragment-length-polymorphism.

Chenggang, X., Xingxing, R., Zhou F., Ying, F., Yanfen H., Zujie, S.,... \& Jianmin, Z. (2017). Phenotypic characteristics and Genetic diversity of Salmonella enterica serotype Derby isolated from human patients and foods of animal origin. Food borne Pathogens and Disease, 14, No. 10. doi.org/10.1089/fpd.2017.2278

Chowdhury, N., Asakura, M., Neogi, S.B., Hinenoya, A., Haldar, S., Ramamurthy, T., Sarkar, B.L., Faruque, S.M., \& Yamasak, S. (2010). Development of simple and rapid PCRfingerprinting methods for Vibrio cholera on the basis of genetic diversity of the super integron (2010). Journal of Applied Microbiology 109 (2010) 304-312

Cosby, D.E., Cox, N.A., Harrison, M.A., Wilson, J.L., Buhr, R.J., \& Fedorka-Cray, P.J. (2015). Salmonella and antimicrobial resistance in broilers: A review. $J$ Appl Poult Res. 2015; 24: 408-426.

Dilmaghani, M., Ahmadi, M., Zahraei S.T., Talebi, A., \& Darvish Z.R. (2010). PCR-Restriction fragment length polymorphism analysis of fljB gene in Salmonella enterica subspecies enterica serovar Typhimurium isolated from avian. Iranian J Microbiol. 2,178-184.

Feasey, N.A, Dougon, G., Kingsley, R.A., Heyderman, R.S., Gordon, M.A. (2012). Invasive non-typhoidal Salmonella disease: an emerging and neglected tropical disease in Africa. Lancet 379: 2489-2499.doi.10.1016/S0140-6736(11) 61752-2

Guibourdenche, M., Roggentin, P., Mikoleit, M., Fields, P.I., Bockemuh, 1 J., Grimont, P.A., \& Weill, F.X. (2010).

Supplement 2003-2007 (No. 47) to the White- KauffmannLe Minor scheme. Research in Microbiology. 2010;161:2629.doi: 10.1016/j.resmic.2009.10.002

Ibrahim, T., Ngwai, Y.B., Pennap, G.R.I., Ishaleku, D., Tsaku, P.A., Abimiku, R.H., $\quad$ Nkene, I.H., \& Bassey, E.B.

(2019). Antimicrobial Resistance Profile of Salmonella Typhimurium Isolated from Commercial Poultry and Poultry farm handlers in Nasarawa State, Nigeria. Microbiology Research Journal International 28(4):1-12

Issenhuth-Jeanjean, S., Roggentin, P., Mikoleit, M., Guibourdenche, M., Pinna, E, Nair, S., Fields, P.I. \& Weill, F.X. (2014). Supplement 2008-2010 (no. 48) to the WhiteKauffmann-Le Minor scheme. Res. Microbiol. 165: 526-530.

Jiang, H., Dong H., Zhang G., Yu B., Chapman L. R., \& Fields M. W. (2006). Microbial diversity in water and sediment of Lake Chaka, an athalassohaline lake in northwestern China. Appl. Environ. Microbiol. 72, 3832-3845

Khaki, P., Moradi, S.B., \& Elham, E. (2013). PCR-RFLP of isolated Salmonella from poultry with Sau3AI and Hhal restriction endonucleases in Arak. Int J Mol and Clin Microbio $1(2013) 255-260$

Landers, T.F., Cohen, B., Wittum, T.E., \& Larson, E.L. (2012). A review of Antibiotic Use in Food Animals: Perspective, Policy and Potential. Public Health Rep. 127(1):422

Lu, Y., Zhao, H., Sun, J., Liu, Y., Zhou, X. \& Beier, R. C. (2014). Characterization of multidrug-resistant Salmonella enterica serovars Indiana and Enteritidis from chickens in Eastern China. PLoS ONE 9:e96050.

Matsui, T., Matsuda, M., Murayama, O., Miller, B.B., \& Moore, J.E., (2001). RecA genotyping of Salmonella enteriditis phage type4 isolates by restriction fragment length polymorphism analysis. Lett Appl Microbiol. 32, 424-427.

Moradi, S., Cheraghchi, N., Khaki, P, \& Sabokbar, A. (2014). Identification of isolated Salmonella enterica serotype gallinarum biotype pullorum and gallinarum by PCR-RFLP. Jundishapur journal of microbiology, 7(9):e19135

Mukherjee, S., Anderson, C.M., Mosci, R.E., Newton, D.W., Lephart, P., Salimnia, H., Khalife, W., Rudrik, J.T., \& Manning, S.D. (2019). Increasing frequencies of antibiotic resistant non-typhoidal Salmonella infections in Michigan and risk factors for disease Front. Med. Retrieved from https://doi.org/10.3389/fmed.2019.00250

Neslihan, T. K., Fatima, N.Y., Nefise A., \& Mustafa, A. (2018).Genetic diversity of food originated Salmonella 
isolates. Biotechnology \& Biotechnologival equipment. $32(3)$,

645.doi:10.1080/13102818.2018.1451779.

Oyinloye, J.M. (2011). Extended spectrum beta-lactamase (ESBL) - producing Multidrug resistant Enterobacteriaceaea from commercial Poultry feeds in Nigeria. Annals of Biological Research, 2:250-254

Rabsch, W., Andrews, H.L., Kingsley, R.A., Prager, R., Tschape, H., Adams, G.L., \& Baurmier, A. J. (2002) Salmonella enterica serotype Typhimurium and its hostedadapted variants. Infection and immunity, 70 (5) 2249-2255.

Shaikh, S., Fatima, J., Shakil, S., Mohd, .S., Rizvi, D., \& Kamal, A.J. (2015). Antibiotic resistance and extended spectrum beta-lactamases: Types, epidemiology and $90-101$ treatment. Saudi Journal of Biological Sciences (22),

Scallan, E., Hoekstra, R.M., Angulo, F.J., Tauxe, R.V., Widdowson, M.A. \& Roy, S.L. (2011). Foodborne illness acquired in the United States-major pathogens. Emerg. Infect. Dis. 17 (1): 7-15.
Soler-García, A. A., De Jesús, A. J., Taylor, K., \& Brown, E. W. (2014). Differentiation of Salmonella strains from the SARA, SARB and SARC reference collections by using three genes PCR-RFLP and the 2100 Agilent Bioanalyzer. Frontiers in microbiology, $4, \quad 417$. https://doi.org/10.3389/fmicb.2014.00417

Sumithra, T.G., Chaturvedi, V.K., \& Gupta, P.K (2014). PCRRFLP analysis of fliC, fimH Band 16s $\mathrm{r}$ RNA genes in Salmonella Typhimurium isolates of varied origin. Ann Microbiol. 2014; 64:177-183.

Turki Y., Mehri I., \& Fhoula I. (2014). Comparison of five molecular subtyping methods for differentiation of Salmonella Kentucky isolates in Tunisia. World J Microbiol Biotechnol. 2014;30:87-98

Zaki, S., Abd-El-Haleem, D., \& El-Helow, E (2009). Molecular and Biochemical diagnosis of Salmonella in waste water. $J$ Appl Sci Environ Manage.2009;13:83-92

World health organization. (WHO). (2018). Non-typhoidal Salmonella. Retrieved from: https://www.who.int/newsroom/fact-sheets/detail/Salmonella- (non-typhoidal). 